\title{
Clinical Management of Women with Newly Diagnosed Osteoporosis: Data from Everyday Practice in Bulgaria
}

\author{
Mihail A. Boyanov (D) - Anna-Maria Borissova - Tzvetanka P. Petranova (D) • \\ Plamen R. Popivanov · Rumen M. Stoilov (D) · Reneta T. Petkova
}

Received: July 14, 2021 / Accepted: August 5, 2021 / Published online: September 6, 2021

(C) The Author(s) 2021

\begin{abstract}
Introduction: The real duration of osteoporosis treatment in clinical practice is still not well described. The primary objective is to estimate the proportion of patients who stayed on treatment during a 4-year follow-up, and the secondary objective is to estimate the proportion of patients who switched treatment and the reasons for switch or discontinuation.

Methods: This was a national retrospective chart review, based on routine clinical data. Data were collected electronically from medical
\end{abstract}

Supplementary Information The online version contains supplementary material available at https:// doi.org/10.1007/s40744-021-00358-0.

M. A. Boyanov

Clinic of Endocrinology and Metabolic Diseases, University Hospital "Alexandrovska", Sofia, Bulgaria

M. A. Boyanov

Department Internal Medicine, Faculty of Medicine, Medical University Sofia, Sofia, Bulgaria

e-mail: mihailboyanov@yahoo.com

A.-M. Borissova

Clinic of Endocrinology, Medical Faculty, Sofia

University "Saint Kliment Ohridski", Sofia, Bulgaria

e-mail: anmarbor@abv.bg

T. P. Petranova

Clinic of Rheumatology, University Hospital

"St.Ivan Rilsky", Medical University, Sofia, Bulgaria

e-mail: dr_petranova@yahoo.com records in 33 representative primary care physicians' sites. Inclusion criteria were women with postmenopausal osteoporosis that have received initial treatment prescription following diagnosis by DXA between January 1, 2012 and December 31, 2014, and at least a 12-month database history after the index date. Exclusion criteria were women receiving treatment for osteoporosis and follow-up at secondary care physicians' sites only. All statistical analyses were performed with the $\mathrm{R}$ statistical package.

Results: A total of 1206 female patients with newly diagnosed osteoporosis and treatment initiation were followed for 4 years. The majority $(88.3 \%)$ had no history of previous fractures. Bone mineral density data were available in

P. R. Popivanov

Clinic of Osteodensitometry and Bone Metabolic

Disease, University Hospital "Alexandrovska",

Medical University Sofia, Sofia, Bulgaria

e-mail: ppopivanov@abv.bg

R. M. Stoilov

Clinic of Rheumatology, University Hospital

"St.Ivan Rilsky", Medical University, Sofia, Bulgaria e-mail: rmstoilov@abv.bg

\section{R. T. Petkova $(\bowtie)$}

Department of General Medicine, Amgen, Sofia, Bulgaria

e-mail: rpetkova@amgen.com 
$70.1 \%$. Endocrinology was the most common specialty among prescribing specialists (40.0\%), followed by rheumatology (30.3\%). Bisphosphonates (BPs) were the most common initial treatment $(72.7 \%)$, followed by denosumab (20.1\%). Ibandronate (70.2\%) and alendronate (24.2\%) constituted the majority of all prescribed BPs; 731 patients remained on treatment during the second year (60.6\%), 524 during the third year (43.4\%) and 403 (33.4\%) - at study end (fourth year). In all groups, except that on denosumab, the most common reason for switching to another treatment was presumed lack of effect. The main reasons for treatment discontinuation were financial on the patient's part.

Conclusions: The duration of osteoporosis treatment in real-world clinical practice is far from optimal: $<3-4$ years irrespective of fracture risk. Factors other than medical considerations are at play, mainly limitations set by the Health Insurance Fund. The health authorities should be aware of this.

Keywords: Duration; Osteoporosis treatment; Primary/secondary care physicians

\section{Key Summary Points}

The real duration of osteoporosis treatment in clinical practice is still not well described.

The duration of osteoporosis treatment in real-world clinical practice may be far from optimal: $<3-4$ years, irrespective of fracture risk. Factors other than medical considerations are at play.

Targeted efforts are needed to close the treatment gap in osteoporosis and to ensure the optimal duration of the prescribed therapeutic options.

\section{INTRODUCTION}

The prevalence of osteoporosis increases with age in both men and women [1]. Data from the largest epidemiological osteoporosis survey in Bulgaria identified $16.8 \%$ of women aged 50 years or older to have osteoporosis at the femoral neck (FN) [2]. The lifetime probability of a hip fracture in Bulgarian women above the age of 50 years was estimated to be $11.2 \%$ in a more recent survey [3]. In addition, a large treatment gap was described-95\% of Bulgarian postmenopausal women (PMO) women expected to have osteoporosis remained without treatment [1]. This treatment gap is one of the largest in Europe as a recent study described a mean gap of $74.6 \%$ in European countries, rising from 53\% in Ireland to 91\% in Germany [4].

In Bulgaria, osteoporosis treatment is reimbursed by the National Health Insurance Fund only if initiated by specialists-secondary care physicians (SCP), such as endocrinologists and rheumatologists, after referral by the primary care physician (PCP) [5]. Bone mineral density (BMD) measurement by dual-energy X-ray absorptiometry (DXA), although not reimbursed, is required at treatment initiation and once yearly as per scientific guidelines [6]. PCPs are then responsible for all prescriptions and patients to ensure continuity of care. All patients should ideally return to the SCP once annually for assessment of treatment response [6]. The PCPs would typically follow the initial recommendation but a good proportion would subsequently stop or switch treatment without re-consultation by the SCP. A small proportion of patients may take the initiative and have regular consultations with specialists, but in this scenario, the visit must be fully covered by the patient. Many factors might affect the osteoporosis management led by the PCPfrom the physicians' personal views on the disease priority to continuity in the diagnostic and therapeutic process $[7,8]$.

No local data exist on how many patients continue their treatment after osteoporosis diagnosis by the SCP. A previous observational study included women with postmenopausal osteoporosis (PMO) who visited only SCP offices 
on a yearly basis for consultation [9]. Results showed that very few patients receiving denosumab discontinued therapy compared with patients receiving ibandronate. However, this study in the SCP setting was not generalizable to patients treated in primary care.

We hypothesized that many patients discontinue treatment or switch to other medications without re-consultation with SCPs. In view of the lack of information about current patterns of osteoporosis treatment at primary care, the primary objective of this study was to estimate the proportion of women who stayed on the treatment prescribed by the SPC during a 4-year follow-up.

The secondary objectives were: (1) to estimate the proportion of patients whose SCPrecommended therapy had been stopped or switched by the PCP, and (2) to estimate the reasons for therapy switch or discontinuation.

\section{METHODS}

\section{Study Design}

The study was conducted as a national observational retrospective chart review based on routine clinical data of PMO women in Bulgaria and was therefore descriptive in nature with no formal hypothesis to be tested. It was performed in accordance with the Helsinki Declaration of 1964 and its later amendments. The study was in accordance with all local legal and regulatory requirements and followed generally accepted research practices. The study protocol was approved by the Central Ethics Medicines Committee of the Bulgarian Regulatory Agency (№НИП-0003/28.02.2019 and №ККИ/СТ-0364/ 08.05.2019). Due to the retrospective nature of this study, informed consent was not required. First data were included in the electronic CRF on 12.05.2019 and with closed out on 25.05.2020.

\section{Participants}

The study was performed in 33 representative (country-specific) sites with large PCP practices.
Sites were selected from the available 4200 PCPs registered in Bulgaria, following feasibility assessment of the study in each one of them. The main site selection criterion was the high turnover of patients with osteoporosis-at least 50 per month. The sites were equally distributed across the country to avoid possible selection bias. The patients, whose data were included in the electronic database and subject of analysis, fulfilled the following criteria.

\section{Inclusion Criteria}

(1) PMO women with initial treatment prescription by SCP following diagnosis by DXA spanning from January 1, 2012, to December 31, 2014; and (2) Patients attending the practice regularly throughout at least 12 months after treatment initiation (in order to reliably describe treatment patterns and cessation); and (3) Patients that fulfilled their prescription at least during the first year after treatment initiation.

\section{Exclusion Criterion}

Women receiving treatment for osteoporosis (OP) and follow-up at SCP sites only. This criterion was introduced as a focus on the management of osteoporosis specifically by PCPs (general practitioners) after the introductory consultation by the SCPs. In addition, this ensured the completeness and continuity of data, as the PCPs had documented the overall health condition of their patients (co-morbidities, etc.).

Baseline characteristics were assessed on the index date of the initial treatment recommendation by the SCP. Patient data were collected from the time of diagnosis (by an SCP) for up to 4 years in the PCP setting, or until the first of death or loss to follow-up.

\section{Data Analysis}

Twelve hundred patients was found to be the minimal sample size sufficient to provide satisfying precision of the interval estimates for the primary objective in the worst case (half $\mathrm{CI}=$ $2.8 \%$ for $p=0.5$ ). 
Data used during the study were collected electronically from subject medical records through a dedicated study application and were then stored in a database in compliance with the requirements of FDA document 21 CFR part 11.

All statistical analyses were performed using the $\mathrm{R}$ statistical package in version 3.6.2 $[10,11]$. All data were descriptive in nature. Categorical variables were displayed as the number and percentage of patients in each category-e.g., by groups after the first, second, third, and fourth years for outcome targets, etc. For categorical variables, the absolute (counts) and relative (\%) frequency of patients in each category was presented. For continuous variables, number of observations, mean, median, standard deviation, quartiles 1 and 3 , range (minimum and maximum), and the number with missing data were reported. Statistical significance was set as two-tailed $p \leq 0.05$.

Inferential analysis for comparison between treatments was not included in the study objectives. It was not performed post hoc due to the relatively small proportions of patients remaining on treatment and the frequent switches and therapy re-initiation.

\section{RESULTS}

\section{Primary and Secondary Care Physicians Providing Patient Data}

Thirty-three PCPs were approved for study participation and granted access to their electronic databases. On average, PCPs had 23.1 (SD 6.0) years of practice with a range of 8 to 36 years (Q1, 19.0, Q3, 27.0 years) and a median of 20 years. Endocrinology was the most common specialty among SCPs $(40.0 \%)$, followed by rheumatology (30.3\%), orthopedics $(14.2 \%)$, and internal medicine (10.2\%).

\section{Patient Characteristics}

A total of 1266 female patients enrolled, 1206 of whom matched the trial criteria entered the analysis. The mean age of the patients was 66.0
(SD 8.6) years, ranging from 39 to 93 years (Q1, 60 years, Q3, 72 years). The youngest patients ( $<65$ years) constituted the majority $(45.6 \%)$ of the research population, followed by the group between 65 and 75 years old (37.2\%). The oldest patients ( $\geq 75$ years) formed the smallest subgroup in the trial $(17.2 \%)$. The patents' mean weight was $68.1 \mathrm{~kg}$ (SD 11.1; $N=1173$ ), range $40-122 \mathrm{~kg}(\mathrm{Q} 1,60.0, \mathrm{Q} 3,74.0 \mathrm{~kg})$. The mean BMI was $26.4 \mathrm{~kg} / \mathrm{m}^{2}$ (SD 4.0; $N=1170$ ), with a range from 17.4 to $44.9 \mathrm{~kg} / \mathrm{m}^{2}$ (Q1, 23.7, Q3, $28.4 \mathrm{~kg} / \mathrm{m}^{2}$ ) and a median of $25.9 \mathrm{~kg} / \mathrm{m}^{2}$. The age at menopause was provided for 538 women only-48.8 years (SD 3.9) and range 26 to 59 years (Q1, 47 years, Q3, 51 years) with a median of 50 years. The menopause had been natural in most women (90\%).

Further details describing the patient group (living situation, employment status, lifestyle factors) are summarized in Supplemental Table 1 . The clinical risk factors of the study participants are summarized in Table 1.

The majority of patients had not experienced previous fractures (88.3\%). Although all patients had baseline DXA scans mandatory for the diagnosis of PMO and treatment initiation BMD results were available in the stored data archives for $70.1 \%$ of the patients only.

Calcium supplementation was used by $67.7 \%$ of patients at baseline, while vitamin $\mathrm{D}$ by $73.6 \%$.

Among all recorded cases of comorbidities at baseline (1578), cardiovascular diseases constituted the majority of cases-787/1578 (49.9\% of all comorbidities) and 787/1206 (63.3\% of all patients). The majority of patients $(78.4 \%)$ were taking concomitant medications.

\section{Initial Osteoporosis Medication Choice}

Among the osteoporosis medications prescribed by the SCPs, bisphosphonates (BPs) was the most common option (72.7\%), followed by denosumab (20.1\%) and strontium ranelate (SR, $6.7 \%)$. In the BPs group, ibandronate (70.2\%) and alendronate $(24.2 \%)$ together constituted the majority of all prescriptions (94.4\%).

Rheumatology was the most frequent specialty among the SCPs (47.3\%) prescribing 
Table 1 Baseline data-clinical risk factors

\begin{tabular}{|c|c|c|}
\hline Baseline variable & Items (levels) & $\begin{array}{l}\text { Number } \\
(N)(\%)\end{array}$ \\
\hline \multirow[t]{2}{*}{ Previous fracture } & Yes & $141(11.7 \%)$ \\
\hline & No & $1065(88.3 \%)$ \\
\hline \multirow[t]{2}{*}{ BMD results available as per documentation } & Yes & $846(70.1 \%)$ \\
\hline & No & $360(29.9 \%)$ \\
\hline \multirow[t]{2}{*}{ Reason for lacking BMD status } & $\begin{array}{l}\text { Patient does not have a copy of DXA } \\
\text { scans }\end{array}$ & $335(93.1 \%)$ \\
\hline & Patient lost to follow-up & $25(6.9 \%)$ \\
\hline \multirow[t]{2}{*}{ Calcium supplementation at baseline? } & Yes & $816(67.7 \%)$ \\
\hline & No & $390(32.3 \%)$ \\
\hline \multirow[t]{2}{*}{ Vitamin D supplementation at baseline? } & Yes & $888(73.6 \%)$ \\
\hline & No & $318(26.4 \%)$ \\
\hline \multirow[t]{2}{*}{ Systemic glucocorticoid use at baseline? } & Yes & $594.9 \%)$ \\
\hline & No & $1147(95.1 \%)$ \\
\hline \multirow[t]{7}{*}{ Secondary osteoporosis due to: } & Anticancer treatment & $6(12.5 \%)$ \\
\hline & Endocrine disorders & $6(12.5 \%)$ \\
\hline & Immobilization & $1(2.1 \%)$ \\
\hline & Kidney diseases & $1(2.1 \%)$ \\
\hline & Other medications & $2(4.2 \%)$ \\
\hline & Rheumatoid arthritis & $32(66.7 \%)$ \\
\hline & Total & $48(100 \%)$ \\
\hline \multirow{12}{*}{$\begin{array}{l}\text { Concomitant diseases at baseline (the most common ones are } \\
\text { listed) }\end{array}$} & Autoimmune & $9(0.6 \%)$ \\
\hline & Cardiovascular & $787(49.9 \%)$ \\
\hline & Central nervous system (CNS) & $84(5.3 \%)$ \\
\hline & Endocrine disease & $16(1.0 \%)$ \\
\hline & Gastrointestinal & $46(2.9 \%)$ \\
\hline & Metabolic & $204(12.9 \%)$ \\
\hline & Musculoskeletal & $24(1.5 \%)$ \\
\hline & Neoplasm & $30(1.9 \%)$ \\
\hline & None & $230(14.6 \%)$ \\
\hline & Renal & $40(2.5 \%)$ \\
\hline & Respiratory & $84(5.3 \%)$ \\
\hline & Total & $1578(100 \%)$ \\
\hline
\end{tabular}


Table 1 continued

\begin{tabular}{lll}
\hline Baseline variable & Items (levels) & $\begin{array}{l}\text { Number } \\
(\boldsymbol{N})(\%)\end{array}$ \\
\hline Concomitant medications (used to treat comorbidities)? & Yes & $945(78.4 \%)$ \\
& No & $261(21.6 \%)$ \\
& Total & $\mathbf{1 2 0 6}(\mathbf{1 0 0 \% )}$ \\
\hline
\end{tabular}

denosumab as the initial treatment $(N=243$, $20 \%$ ). The second most common was endocrinology (25.1\%).

Intravenous BPs (iv BPs) were prescribed mostly by rheumatologists $(N=73,6 \%)$, followed by endocrinologists (28.8\%). Ibandronate was the most common choice $(87.7 \%)$. Zoledronate was rarely used (12.3\%).

Oral BPs were administered mostly by endocrinologists $(N=804,67 \%)$, followed by specialists in rheumatology $(23.5 \%)$ and orthopedics $(17.3 \%)$. Ibandronate was the most frequently prescribed oral BP (68.7\%), followed by alendronate (26.4\%).

The endocrinologists (61.7\%) built the majority of SCP prescribing strontium ranelate $(N=81,6.7 \%)$ followed by rheumatologists (25.9\%).

Table 2 Status of the osteoporosis treatment at study end
A detailed list of SCPs' specialties and treatment choices is presented in Supplemental Table 2.

\section{Patient Disposition}

Figure 1 shows that from all 1206 initiated patients, 731 remained on treatment during the second year $(60.6 \%)$, 524 during the third year (43.4\%) and 403 only (33.4\%) - at study end (fourth year).

The status of the participants at the end of the treatment period is reviewed in Table 2.

\section{Cessation and Substitution of Osteoporosis Medications}

Table 3 summarizes the changes in treatment modality during the study period.

\begin{tabular}{|c|c|c|c|c|c|c|}
\hline \multirow[t]{2}{*}{ Time } & \multicolumn{4}{|l|}{ On treatment } & \multicolumn{2}{|l|}{ No treatment } \\
\hline & $\begin{array}{l}N_{\text {Total }} \\
\text { Initiated }+ \text { Switched }+ \text { Continued }\end{array}$ & $\begin{array}{l}\text { Initiated, } \\
N\end{array}$ & $\begin{array}{l}\text { Switched, } \\
N\end{array}$ & $\begin{array}{l}\text { Continued, } \\
N\left(\%^{*}\right)\end{array}$ & $\begin{array}{l}\text { Non-initiated, } \\
N\left(\%^{*}\right)\end{array}$ & $\begin{array}{l}\text { Stopped, } \\
N\left(\%^{* *}\right)\end{array}$ \\
\hline $\begin{array}{l}1 \text { st } \\
\text { year }\end{array}$ & 1206 & 1206 & 26 & $\begin{array}{l}\text { Not } \\
\text { applicable }\end{array}$ & Not applicable & $475(39.4 \%)$ \\
\hline $\begin{array}{l}\text { 2nd } \\
\text { year }\end{array}$ & 731 & 0 & 43 & $688(57.0 \%)$ & $475(39.4 \%)$ & $217(29.7 \%)$ \\
\hline $\begin{array}{l}\text { 3rd } \\
\text { year }\end{array}$ & 524 & 10 & 15 & 499 (41.4\%) & $682(56.6 \%)$ & $133(25.4 \%)$ \\
\hline $\begin{array}{l}\text { 4th } \\
\text { year }\end{array}$ & 403 & 12 & 15 & $376(31.2 \%)$ & $803(66.6 \%)$ & $\begin{array}{l}\text { Not } \\
\text { applicable }\end{array}$ \\
\hline
\end{tabular}




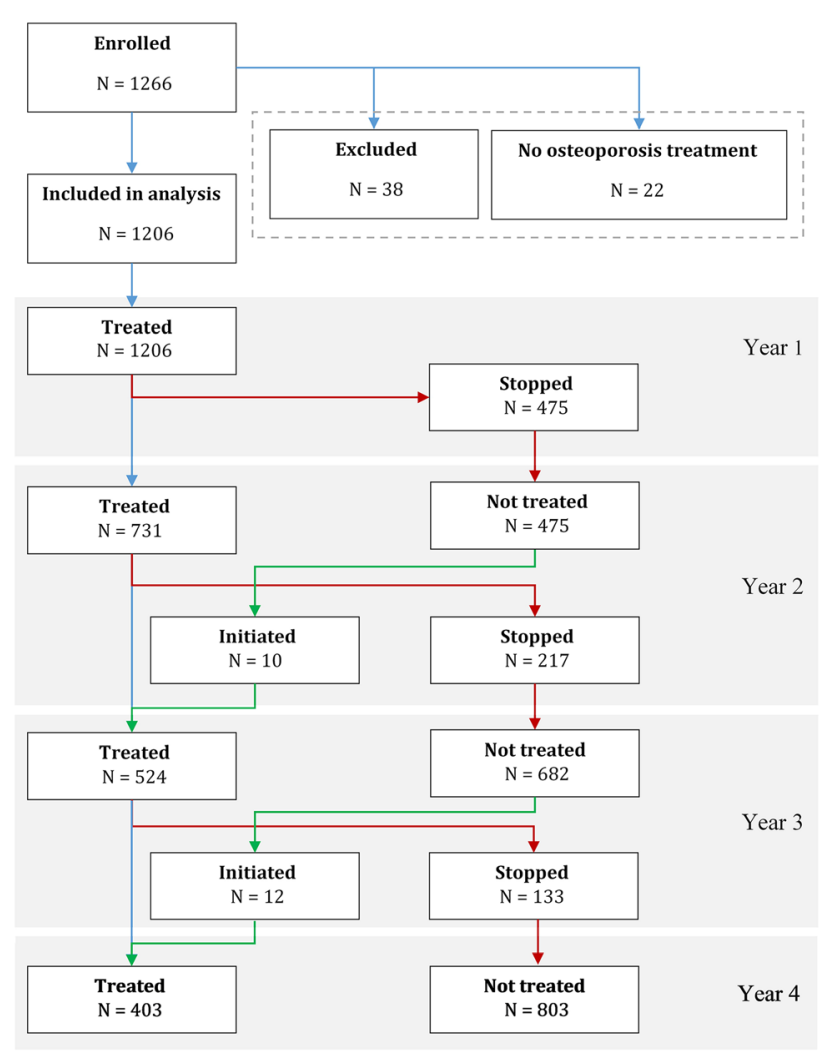

Fig. 1 Summary of the study enrolment

Table 3 Switching between treatment modalities during the study period

\begin{tabular}{lllllll}
\hline Switches, $\boldsymbol{N = 9 4 6}$ & Denosumab & Oral BP & iv BP & SR & Other & No treatment \\
\hline Denosumab & - & $7(0.7 \%)$ & $1(0.1 \%)$ & $1(0.1 \%)$ & 0 & $137(14.5 \%)$ \\
Oral BPs & $48(5.1 \%)$ & - & $7(0.7 \%)$ & $2(0.2 \%)$ & $2(0.2 \%)$ & $575(60.8 \%)$ \\
iv BPs & $12(1.3 \%)$ & $6(0.6 \%)$ & - & $1(0.1 \%)$ & 0 & $47(5.0 \%)$ \\
SR & $6(0.6 \%)$ & $5(0.5 \%)$ & 0 & - & 0 & $62(6.6 \%)$ \\
Other & 0 & $1(0.1 \%)$ & 0 & 0 & - & $4(0.4 \%)$ \\
No treatment & $16(1.7 \%)$ & $2(0.2 \%)$ & $1(0.1 \%)$ & $2(0.2 \%)$ & $1(0.1 \%)$ & - \\
\hline
\end{tabular}

$S R$ strontium ranelate

The fraction of patients for whom the therapy was stopped has decreased over time, from $39.4 \%$ (475) in the first year to $25.4 \%$ (133) in the third year. A big reduction in stopping oral BPs from the first to third years was noted. The most frequently stopped treatment was the oral BP (60.8\%). Stopping denosumab was much rarer $(14.5 \%)$. Stopping treatment was much more frequent than switching. The most frequent switch between treatments, across the entire trial period, was from oral BPs to denosumab (5.1\%). Changes from denosumab to other treatments (excluding the no-treatment option) were less frequent. 
Table 4 Reasons for treatment change and discontinuation according to the treatment options during the 4-year period

\begin{tabular}{|c|c|c|c|c|c|}
\hline Reasons & Items (levels) & $\begin{array}{l}\text { Total } \\
N(\%) \\
N_{\text {Total }}=678\end{array}$ & $\begin{array}{l}\text { Denosumab } \\
N(\%) \\
N_{\text {Total }}=100\end{array}$ & $\begin{array}{l}\text { Oral BPs } \\
N(\%) \\
N_{\text {Total }}=470\end{array}$ & $\begin{array}{l}\text { IV BPs } \\
N(\%) \\
N_{\text {Total }}=49\end{array}$ \\
\hline \multirow[t]{8}{*}{ Reason for treatment change } & $\mathrm{AE}$ related to medication & $5(0.7 \%)$ & N/A & $1(0.2 \%)$ & $2(4.1 \%)$ \\
\hline & Financial reason & $5(0.7 \%)$ & $2(2.0 \%)$ & $3(0.6 \%)$ & N/A \\
\hline & Hospitalization & $2(0.3 \%)$ & $\mathrm{N} / \mathrm{A}$ & $2(0.4 \%)$ & N/A \\
\hline & Investigator's decision & $32(4.7 \%)$ & $9(9.0 \%)$ & $15(3.2 \%)$ & $6(12.2 \%)$ \\
\hline & Lack of effect & $70(10.3 \%)$ & $3(3.0 \%)$ & $44(9.4 \%)$ & $11(22.4 \%)$ \\
\hline & Other & $3(0.4 \%)$ & $\mathrm{N} / \mathrm{A}$ & $3(0.6 \%)$ & N/A \\
\hline & Poor adherence & $16(2.4 \%)$ & $1(1.0 \%)$ & $12(2.6 \%)$ & $3(6.1 \%)$ \\
\hline & SCP decision & $19(2.8 \%)$ & $1(1.0 \%)$ & $14(3.0 \%)$ & $4(8.2 \%)$ \\
\hline \multirow[t]{14}{*}{ Reason for discontinuation } & $\mathrm{AE}$ related to medication & $32(4.7 \%)$ & N/A & $28(6.0 \%)$ & $\mathrm{N} / \mathrm{A}$ \\
\hline & Death & $4(0.6 \%)$ & $1(1.0 \%)$ & $2(0.4 \%)$ & N/A \\
\hline & Financial reason & $196(28.9 \%)$ & $26(26.0 \%)$ & $166(35.3 \%)$ & $2(4.1 \%)$ \\
\hline & Hospitalization & $2(0.3 \%)$ & N/A & $2(0.4 \%)$ & N/A \\
\hline & Investigator decision & $9(1.3 \%)$ & $3(3.0 \%)$ & $5(1.1 \%)$ & $1(2.0 \%)$ \\
\hline & Lack of effect & $18(2.7 \%)$ & $1(1.0 \%)$ & $14(3.0 \%)$ & $\mathrm{N} / \mathrm{A}$ \\
\hline & Lack of supply & $3(0.4 \%)$ & N/A & $3(0.6 \%)$ & $\mathrm{N} / \mathrm{A}$ \\
\hline & Lost to follow-up & $126(18.6 \%)$ & $20(20.0 \%)$ & $60(12.8 \%)$ & $13(26.5 \%)$ \\
\hline & Malignancies & $8(1.2 \%)$ & $3(3.0 \%)$ & $4(0.9 \%)$ & $\mathrm{N} / \mathrm{A}$ \\
\hline & Other & $3(0.4 \%)$ & $\mathrm{N} / \mathrm{A}$ & $2(0.4 \%)$ & $1(2.0 \%)$ \\
\hline & Patient's request & $9(1.3 \%)$ & $3(3.0 \%)$ & $5(1.1 \%)$ & $1(2.0 \%)$ \\
\hline & Poor adherence & $69(10.2 \%)$ & $5(5.0 \%)$ & $55(11.7 \%)$ & $5(10.2 \%)$ \\
\hline & SCP decision & $34(5.0 \%)$ & $3(3.0 \%)$ & $26(5.5 \%)$ & $3(6.1 \%)$ \\
\hline & Unknown & $(19.6 \%)$ & $25(25.0 \%)$ & $88(18.7 \%)$ & $(28.6 \%)$ \\
\hline
\end{tabular}

\section{Reasons for Treatment Change and Discontinuation}

Table 4 shows the reasons for treatment change and treatment discontinuation for all patients who, during the 4-year period of follow-up, have changed their PMO treatment $(N=678)$.

The most common reason for changing the PMO treatment was presumed lack of effect (10.3\% of all patients). This so-called presumed lack of effect was mainly documented as lack of
BMD increase on subsequent DXA scans, which reflected both the poor PCP communication and the wrong patients' perceptions of treatment success.

The most frequent reasons for treatment discontinuation were financial $(28.9 \%)$, being lost to follow-up (18.6\%), and poor adherence $(10.2 \%)$. The most common financial reason was the patient's inability or unwillingness to co-pay $50 \%$ of the treatment cost. Compared to 
Table 5 Supplementation with calcium and vitamin D (combined)

\begin{tabular}{lllc}
\hline Co-treatment & Year & \multicolumn{1}{l}{$\boldsymbol{N}(\%)$} & $\boldsymbol{N}_{\text {Total }}$ \\
\hline Any treatment & 1st & $739(61.3 \%)$ & 1206 \\
& 2nd & $465(63.6 \%)$ & 731 \\
& 3rd & $362(69.1 \%)$ & 524 \\
Denosumab & 4th & $300(74.4 \%)$ & 403 \\
& 1st & $180(70.0 \%)$ & 257 \\
& 2nd & $163(70.0 \%)$ & 233 \\
iv BP & 3rd & $150(70.4 \%)$ & 213 \\
& 4th & $133(74.7 \%)$ & 178 \\
& 1st & $45(60.0 \%)$ & 75 \\
2ral BP & 2nd & $19(37.3 \%)$ & 51 \\
& 3rd & $13(41.9 \%)$ & 31 \\
& 4th & $8(47.1 \%)$ & 17 \\
& 1st & $468(57.6 \%)$ & 813 \\
& 2nd & $270(61.8 \%)$ & 437 \\
& 3rd & $191(70.0 \%)$ & 273 \\
& 4th & $150(76.1 \%)$ & 197 \\
& 1st & $56(69.1 \%)$ & 81 \\
& 2nd & $18(72.0 \%)$ & 25 \\
& 3rd & $11(73.3 \%)$ & 15 \\
& 4th & $11(73.3 \%)$ & 15 \\
\hline & &
\end{tabular}

monthly pensions, this co-payment was not negligible at all.

\section{Initial Treatment: Denosumab}

The number of patients taking denosumab over the 4-year period was dropping from 257 during the first year to 233, 213 and 178 during the second, third and fourth year respectively. However, due to the decreasing overall number of treated patients, the percentage of patients on denosumab had increased from $21.3 \%$ in the first year to $31.9 \%$ in the second, to $40.6 \%$ in the third, and to $44.2 \%$ in the fourth year.
The most common reason for switching from denosumab to another treatment option was an investigator's decision (9.0\%). The most frequent reasons for denosumab discontinuation were financial ones $(26.0 \%)$ and failure to appear $(20.0 \%)$.

Initial Treatment: BPs The most common reason for changing the oral $\mathrm{BP}$ treatment was presumed lack of effect $(9.4 \%)$, while the most common reason for discontinuation was again financial in origin $(35.3 \%)$, followed by failure to appear (in $12.8 \%$ ), and poor adherence (in $11.7 \%)$.

The most common reason for switching from iv BPs to other treatment options was the presumed lack of effect (in 22.4\%) followed by an investigator's decision (12.2\%). In the iv BPs subgroup, the most frequent reason for treatment discontinuation was failure to appear $(26.5 \%)$ and poor adherence $(10.2 \%)$.

Treatment Changes Occurring Due to Differing Recommendations by the PCP AND SCP

There were two patients $(2 / 1206=0.17 \%)$ who had their SCP-recommended therapy switched by the PCP without the re-evaluation by the SCP.

There was a single patient $(1 / 1206=0.08 \%)$ who received denosumab by the SCP, but the PCP recommended oral BP for a financial reason.

Overall treatment prescribing and monitoring of OP could be done with an overhaul, with PCPs having the leading role and SCPs-the supportive one.

\section{Calcium and Vitamin D Supplementation}

Table 5 summarizes the percentage of patients with full supplementation (both calcium and vitamin $\mathrm{D}$ at the same time) over the consecutive 4 years, split by the co-treatment administered at the time of the supplementation. A common pattern except for the i.v. BP group is that the percentage of supplemented patients was higher in the first year and either increased over time, or remained stable. However, the total number of patients dropped each year and 
Table 6 Information on reported fractures

\begin{tabular}{|c|c|c|}
\hline Variable & Value & $N(\%)$ \\
\hline Period & 1st year & $10(0.8 \%)$ \\
\hline \multirow{4}{*}{$\begin{array}{l}\text { Number of patients with } \\
\text { fracture at given year }\end{array}$} & $N_{\text {Total }}=1206$ & \\
\hline & $\begin{array}{l}2 \text { nd year } \\
\qquad N_{\text {Total }}=731\end{array}$ & $5(0.7 \%)$ \\
\hline & $\begin{array}{l}3 \text { rd year } \\
N_{\text {Total }}=524\end{array}$ & $9(1.7 \%)$ \\
\hline & $\begin{array}{l}\text { 4th year } \\
\qquad N_{\text {Total }}=403\end{array}$ & $6(1.5 \%)$ \\
\hline \multirow[t]{12}{*}{ Fracture location } & Ankle & $1(3.3 \%)$ \\
\hline & Cheekbone & $1(3.3 \%)$ \\
\hline & Clavicle & $1(3.3 \%)$ \\
\hline & Elbow & $1(3.3 \%)$ \\
\hline & Foot & $3(10.0 \%)$ \\
\hline & Forearm & $4(13.3 \%)$ \\
\hline & Hip & $2(6.7 \%)$ \\
\hline & Pubis & $1(3.3 \%)$ \\
\hline & Ribs & $2(6.7 \%)$ \\
\hline & Vertebral & $7(23.3 \%)$ \\
\hline & Wrist & $6(20.0 \%)$ \\
\hline & Other & $1(3.3 \%)$ \\
\hline \multirow{2}{*}{$\begin{array}{l}\text { Hospitalization due to } \\
\text { the fracture }\end{array}$} & Yes & $9(30.0 \%)$ \\
\hline & No & $21(70.0 \%)$ \\
\hline \multirow[t]{4}{*}{ Hospitalization duration } & $\leq 3$ days & $2(22.2 \%)$ \\
\hline & $\leq 7$ days & $6(66.7 \%)$ \\
\hline & more & $1(11.1 \%)$ \\
\hline & Total & $9(100 \%)$ \\
\hline \multirow{3}{*}{$\begin{array}{l}\text { Physiotherapy due to the } \\
\text { fracture }\end{array}$} & Yes & $18(60.0 \%)$ \\
\hline & No & $12(40.0 \%)$ \\
\hline & Total & $30(100 \%)$ \\
\hline
\end{tabular}

Table 6 continued

\begin{tabular}{llr}
\hline Variable & Value & \multicolumn{1}{c}{$\boldsymbol{N}(\%)$} \\
\hline Physiotherapy duration & $\leq 7$ days & $8(44.4 \%)$ \\
& $\leq 1$ month & $7(38.9 \%)$ \\
& $\leq 3$ months & $3(16.7 \%)$ \\
& Total & $18(100 \%)$ \\
\hline
\end{tabular}

Three patients experienced fracture at more than 1 year ${ }^{*}$ Number of patients with at least one fracture in the 4-year period is $N=27$

so did the number of supplemented patients, thus keeping the percentages on stable or slightly increasing trend.

\section{Bone Mineral Density (BMD) Data}

A baseline DXA measurement had been performed in all patients, however BMD data of only 846 patients $(70.1 \%)$ had been stored in the databases. In the second year, the number of patients with DXA measurements dropped to 108 out of 731 still on treatment (14.8\%), in the third year-to 94 out of 524 on treatment (17.9\%) and to 78 out of 403 (19.4\%) within the fourth year. Therefore, the regular annual controls of BMD were the exception rather than the rule.

Only data of patients who had neither changes nor gaps during the treatment were analyzed in an attempt to make T-scores more reliable. There was a large imbalance between the baseline (846) and subsequent years (78-108). There were a lot of improvements in the $T$-score over time, but no patient in neither test location nor treatment group crossed the -1.5 cutoff, and only a few crossed the -2.0 cutoff. Detailed results can be found in Supplemental Fig. 1.

\section{Osteoporotic Fractures}

Table 6 shows the data on reported fractures. In total, 30 fractures were recorded in 27 patients during the 4-year period. Three patients 
experienced more than one fracture; $33 \%$ of fractures occurred in the first year and 30\% in the third year. The most common fracture locations were the spine $(23.3 \%)$ and the wrist (20\%). Both of these locations accounted for almost half of all fractures.

The absolute numbers of fractures were too small to allow any comparisons between the different treatments.

\section{DISCUSSION}

This study analyzed 1206 female patients with newly diagnosed osteoporosis who were followed for 4 years. The majority of them (88.3\%) had no history of previous fractures. BMD results were available per documentation in $70.1 \%$. Calcium supplementation was used by $67.7 \%$ of patients at baseline, while vitamin D by $73.6 \%$. Endocrinology was the most common specialty among prescribing SCPs (40.0\%), followed by rheumatology (30.3\%). Bisphosphonates (BPs) were the most common initiated treatment $(72.7 \%)$, followed by denosumab (20.1\%). Ibandronate (70.2\%) and alendronate $(24.2 \%)$ together constituted the majority of all prescriptions in the BPs group. From all initiated 1206 patients, 731 remained on treatment during the second year $(60.6 \%), 524$ during the third year $(43.4 \%)$, and 403 only $(33.4 \%)$ at study end (fourth year). In all groups, except the one on denosumab, the most common reason for switching the osteoporosis treatment was lack of effect. In the denosumab subgroup, it was an investigator's decision. Regarding the treatment discontinuation, the main reasons were financial in origin, plus poor adherence and patient's failure to appear. The main conclusion was that despite all efforts, the osteoporosis treatment was applied for very short and insufficient periods of time.

Timely prescription of osteoporosis medications and proper adherence to therapy are the key factors in the strategy to reduce the risk of fragility fractures, as once again highlighted in the most recent scorecard for osteoporosis in Europe [12]. The systematic and active cooperation among the medical specialists involved in the continuous process of osteoporosis diagnosis and treatment is of vital importance. In addition, factors of administrative and financial character may play a pivotal role. The initial prescription (oriented mainly after BMD $T$-scores) of appropriate anti-osteoporotic medications in our country is restricted to specialists in rheumatology and endocrinology only $[5,6]$. The BMD scan is not reimbursed. In addition, the patient's access to the specialists is affected by the general practitioner's assessment and referral. The number of referrals to specialists is also limited by the National Health Insurance Fund [5]. Treatment of osteoporosis could be subject of specialist's follow-up once in 2 years, but the referral for this secondary assessment (limited in number) is again left in the field of the general practitioners [5]. Sometimes it is easier for them to stop the treatment rather than to initiate a costly re-assessment. The modest level of medication reimbursement (50\%) and the lack of reimbursement for DXA measurements render the situation even worse.

The role of the GP as coordinator and facilitator of the anti-osteoporotic strategy is crucial. Many studies reported barriers and gaps in osteoporosis treatment led by GPs [13-16]. A Spanish survey reported $63.4 \%$ of inadequacy in the diagnosis and treatment of osteoporosis [13]. Only $40.3 \%$ of those with indications for treatment received BPs and $47.9 \%$ with calcium and vitamin D. In our study, about two-thirds of all treated patients received proper supplementation. A follow-up survey among Czech GPs revealed that only $60 \%$ of the respondents were adherent to the guidelines [15]. Calcium supplementation was started by $41 \%$ of the respondents and vitamin D by $40 \%$ only. This study focused attention to the lack of possibility to prescribe selected drugs (in 61\%) and the financial limits introduced by the health insurance authorities (44\%) [15]. All of this increased the financial burden on the patient in addition to the low willingness of patients to pay for drugs out of pocket [15]. Two studies looking at the barriers to improvement in GPs revealed that GPs considered osteoporosis far less important than other diseases and shared their uncertainties about the interpretation of BMD tests $[7,16]$. In another study, the presence of major osteoporotic risk factors did not alter the 
likelihood for diagnostic and therapeutic interventions [14].

Another crucial factor for the selection of osteoporosis medications is the specialty of the prescribing physician. Our study showed some differences in drug preferences with endocrinologists prescribing much more often strontium ranelate than rheumatologists. Of note, the time period we analyzed was just before the classification of strontium salts as a third-line treatment option. A large registry-based study highlighted the role of the prescribing specialist [17]. According to this, specialists were more likely to prescribe a treatment other than oral bisphosphonates. The primary adherence to the prescribed treatment was higher with GPs (prescribing primarily oral BPs), but secondary adherence did not differ between GPs and specialists [17].

In our study, the percentage of patients on denosumab increased with time, primarily due to the generally decreasing number of patients still on treatment. The continuous use of BPs and denosumab in older adults was explored in more than one study $[18,19]$. In 100,000 newly initiated older adults in Canada, the duration of denosumab use was longer than that of BPs [18]. In this particular study, more BP users had discontinued therapy at day $365(56.7 \%)$ than had the denosumab users (33.8\%) [18]. An Irish study including 44 general practices reported 2-year persistence of $49.4 \%$ for oral BPs and $53.8 \%$ for denosumab [19]. Of note, less than $10 \%$ of the participants had been switched to other medications [19].

The patients' beliefs and concerns contribute largely to the worsening adherence to the osteoporosis treatment. A study following women treated with BPs documented variable reasons for discontinuation: withdrawal by another physician (40\%), lack of motivation $(20 \%)$, absence of BMD increase $(14 \%)$, and many others [20]. In a previous retrospective, observational, multicenter chart review (with up to 24 months of follow-up) we analyzed postmenopausal women initiating 6-monthly denosumab injection or monthly oral ibandronate treatment [9]. At 24 months, $4.5 \%$ of women receiving denosumab had discontinued therapy compared with $56.2 \%$ of women receiving ibandronate. Median time to discontinuation was longer in the denosumab group (729 days; interquartile range (IQR), 728.3-729.0) than in the ibandronate group (367 days; IQR, 354.0-484.8; $p<0.001$ ). This previous study, however, included only two medications and the participants were followed by specialists dedicated to the management of osteoporosis [9].

The limitations of the present study are inherent to its observational and retrospective nature. Using post hoc data extracted from registries may be the source of the bias and missing data.

The major strength of this study lies in the fact that it reflects the real-world situation in the management of osteoporosis in our country. Despite accumulating evidence of high fracture risk in subgroups of the Bulgarian population [3], adherence to treatment is not rising. The combination of medical and nonmedical factors (e.g., level and criteria for reimbursement) is directly compromising the proper management of osteoporosis in our country. Higher public awareness, higher reimbursement of DXA tests, and osteoporosis drugs might contribute to an improvement of the osteoporosis care and to closing the wide gap in fracture prevention. Different strategies for solving these problems have already been tried: issuing osteoporosis guidelines dedicated to GPs [21], testing priorities in specific focus groups [22], as well as introducing remote consultations (telemedicine), which would help a lot in the present COVID-19 era [23].

\section{CONCLUSIONS}

The duration of osteoporosis treatment in realworld clinical practice is far from being optimal, usually below 3-4 years irrespective of fracture risk. Factors other than medical considerations are at play-regulations and limitations set by the Health Insurance Fund, patient's willingness and ability to pay out-of-pocket costs, and many others. The health authorities should be aware of the barriers to the proper prevention of the costly fragility fractures. We still need to 
improve our strategy for treatment gap closure and proper patient's retention on treatment.

\section{ACKNOWLEDGEMENTS}

The authors wish to thank all of the physicians and their office staff participating in this study.

Funding. Amgen (Europe) GmbH designed the study in cooperation with the authors and provided financial support for the study and statistical analysis, including the journal's Rapid Service Fee.

Authorship. All named authors meet the International Committee of Medical Journal Editors (ICMJE) criteria for authorship for this article, take responsibility for the integrity of the work, and have given their approval for this version to be published.

Author Contributions. MAB and RP contributed to conception and design of the study. All authors contributed equally to the acquisition, analysis, and/or interpretation of data. MAB and RP drafted the manuscript with RP providing editorial assistance. All authors critically revised the manuscript versions, accepted the final version before submission, and agreed to be accountable for all aspects of work ensuring integrity and accuracy.

Disclosures. MAB has received speaker fees from MSD, Novartis, Roche, Amgen, Merck, and Aventis, and honoraria for advisory board meetings from Amgen and MSD. AMB has received speaker fees from Novo Nordisk, Eli Lilly, Sanofi, MSD, Merck, Berlin Chemie, Servier, Boehringer Ingelheim, Astra Zeneca, Roche, Novartis, Amgen, and honoraria for advisory board meeting from Eli Lilly, Sanofi, MSD, Boehringer Ingelheim, Astra Zeneca, Amgen. TPP has received speaker fees from AbbVie, UCB, Pfizer, Elly Lilly, MSD, Novartis, Roche, and Amgen, and honoraria for advisory board meetings from AbbVie, Pfizer, Elly Lilly, Novartis, Amgen, and MSD. RMS has received speaker fees from Boehringer Ingelheim Amgen,
AbbVie, Pfizer, honoraria for Advisory Board from Lilly, Pfizer and Janssen. PRP has received speaker fees from Elly Lilly, Novo Nordisk, Amgen, Boehringer Ingelheim, Berlin-Chemie, MSD, and honoraria for advisory board meetings from Elly Lilly, Novo Nordics, Amgen, Boehringer Ingelheim, Sanofi, MSD. RTP is an Amgen employee and Amgen stockholder.

Compliance with Ethics Guidelines. The study was conducted in accordance with all local legal and regulatory requirements and followed generally accepted research practices. In agreement with national law, the study protocol was approved by the Central Ethics Medicines Committee of the Bulgarian Regulatory Agency (№̈ИП-0003/28.02.2019 and №ЕККИ/СТ-0364/08.05.2019). Due to the retrospective nature of this study, informed consent was not required. First data were included in the electronic CRF on 12.05.2019 and last ones on 25.05.2020.

Data Availability. Qualified researchers may request data from Amgen clinical studies. Complete details are available at the following: http://www.amgen.com/datasharing.

Open Access. This article is licensed under a Creative Commons Attribution-NonCommercial 4.0 International License, which permits any non-commercial use, sharing, adaptation, distribution and reproduction in any medium or format, as long as you give appropriate credit to the original author(s) and the source, provide a link to the Creative Commons licence, and indicate if changes were made. The images or other third party material in this article are included in the article's Creative Commons licence, unless indicated otherwise in a credit line to the material. If material is not included in the article's Creative Commons licence and your intended use is not permitted by statutory regulation or exceeds the permitted use, you will need to obtain permission directly from the copyright holder. To view a copy of this licence, visit http://creativecommons.org/licenses/bync/4.0/. 


\section{REFERENCES}

1. Svedbom A, Hernlund $\mathrm{E}$, Ivergård $\mathrm{M}$, Compston $\mathrm{J}$, Cooper C, Stenmark J, et al. EU Review Panel of IOF. Osteoporosis in the European Union: a compendium of country-specific reports. Arch Osteoporos. 2013;8(1):137.

2. Borissova AM, Rashkov R, Boyanov M, Shinkov A, Popivanov $\mathrm{P}$, Temelkova $\mathrm{N}$, et al. Femoral neck bone mineral density and 10-year absolute fracture risk in a national representative sample of Bulgarian women aged 50 years and older. Arch Osteoporos. 2011;6:189-95.

3. Kirilova E, Johansson $\mathrm{H}$, Kirilov N, Vladeva $\mathrm{S}$, Petranova T, Kolarov Z, et al. Epidemiology of hip fractures in Bulgaria: development of a countryspecific FRAX model. Arch Osteoporos. 2020;15(1): 28.

4. McCloskey E, Rathi J, Heijmans S, Blagden M, Cortet B, Czerwinski E, Hadji P, Payer J, Palmer K, Stad R, O'Kelly J, Papapoulos S. The osteoporosis treatment gap in patients at risk of fracture in European primary care: a multi-country cross-sectional observational study. Osteoporos Int. 2021;32(2):251-9.

5. National Health Insurance Fund. Requirements for osteoporosis treatment of outpatients - active since June 1st, 2016; https://www.nhif.bg/page/207 (item 27).

6. Bulgarian Society of Endocrinology. Guideline for good clinical practice in osteoporosis, 2019; https:// endo-bg.com/dobri-praktiki/.

7. Salminen H, Piispanen P, Toth-Pal E. Primary care physicians' views on osteoporosis management: a qualitative study. Arch Osteoporos. 2019;14(1):48.

8. Roblin DW, Cram P, Lou Y, Edmonds SW, Hall SF, Jones MP, Saag KG, Wright NC, Cromwell LF, Robinson BE, Wolinsky FD, PAADRN Investigators. The contribution of patient, primary care physician, and primary care clinic factors to good bone health care. Perm J. 2021;25:1-3.

9. Petranova T, Boyanov M, Shinkov A, Petkova R, Intorcia M, Psachoulia E. Medication-taking behaviour in Bulgarian women with postmenopausal osteoporosis treated with denosumab or monthly oral bisphosphonates. Arch Osteoporos. 2017;13(1): 1.

10. R Core Team (2019). R: A language and environment for statistical computing. R Foundation for Statistical Computing, Vienna, Austria. URL https://www.R-project.org/.
11. R: Regulatory Compliance and Validation Issues - A Guidance Document for the Use of $\mathrm{R}$ in Regulated Clinical Trial Environments, March 25, 2018, The R Foundation for Statistical Computing c/o Institute for Statistics and Mathematics Wirtschaftsuniversitat Wien Welthandelsplatz 11020 Vienna, Austria, https://www.r-project.org/doc/R-FDA.pdf

12. Kanis JA, Norton N, Harvey NC, Jacobson T, Johansson H, Lorentzon M, McCloskey EV, Willers C, Borgström F. SCOPE 2021: a new scorecard for osteoporosis in Europe. Arch Osteoporos. 2021;16(1):82.

13. Vedia Urgell C, Massot Mesquida $M$, Valles Fernandez R, Garcia Vicente JA, Franzi Siso A, Muñoz Ortiz L, et al. Adecuación del tratamiento de la osteoporosis en prevención primaria. Estudio cuantitativo y cualitativo [Adequacy of treatment for osteoporosis in primary prevention. Quantitative and qualitative study]. Aten Primaria. 2018;50(1):6-15.

14. Mendis AS, Ganda K, Seibel MJ. Barriers to secondary fracture prevention in primary care. Osteoporos Int. 2017;28(10):2913-9.

15. Vytrisalova M, Touskova T, Fuksa L, Karascak R, Palicka V, Byma S, et al. How general practitioners and their patients adhere to osteoporosis management: a follow-up survey among Czech general practitioners. Front Pharmacol. 2017;8:258.

16. Merle B, Haesebaert J, Bedouet A, Barraud L, Flori $\mathrm{M}$, Schott AM, et al. Osteoporosis prevention: Where are the barriers to improvement in French general practitioners? A qualitative study. PLoS ONE. 2019;14(7): e0219681.

17. Hitz MF, Arup S, Holm JP, Soerensen AL, Gerds TA, Jensen JB. Outcome of osteoporosis evaluation, treatment, and follow-up in patients referred to a specialized outpatient clinic compared to patients in care of general practitioners. Arch Osteoporos. 2020;15(1):97.

18. Clemens KK, Jeyakumar N, Ouédraogo AM, Thain J, Khan T. Bisphosphonate and denosumab initiation in older adults in Ontario, Canada: a populationbased cohort study. Arch Osteoporos. 2020;15(1): 133.

19. Walsh ME, Fahey T, Moriarty F. Persistence with oral bisphosphonates and denosumab among older adults in primary care in Ireland. Arch Osteoporos. 2021;16(1):71.

20. Donato P, Pepe J, Colangelo L, Danese V, Cecchetti $\mathrm{V}$, Minisola S, et al. Adherence to bisphosphonates in the general population: a study in patients referred to a primary care service. Arch Osteoporos. 2019;14(1):42. 
21. Jothimurugan S, Jothimurugan S, Sanganee D, Wickramaratne T, Lynn M. A pilot project on the management of osteoporosis in primary care: results of the audit cycle. Br J Gen Pract. 2020;70(suppl 1):bjgp20X711653.

22. Hawarden A, Jinks C, Mahmood W, Bullock L, Blackburn S, Gwilym S, Paskins Z. Public priorities for osteoporosis and fracture research: results from a focus group study. Arch Osteoporos. 2020;15(1): 89.

23. Paskins Z, Crawford-Manning F, Bullock L, Jinks C. Identifying and managing osteoporosis before and after COVID-19: rise of the remote consultation? Osteoporos Int. 2020;31(9):1629-32. 